\title{
Anti-CEACAM5 Antibody-Drug Conjugate SAR408701
}

National Cancer Institute

\section{Source}

National Cancer Institute. Anti-CEACAM5 Antibody-Drug Conjugate SAR408701. NCI

Thesaurus. Code C117229.

An immunoconjug ate consisting of anti-carcinoembryonic antigen-related cell adhesion molecule 5 (CEACAM5) conjugated to a cytotoxic agent, with potential antineoplastic activity. Upon administration of anti-CEACAM5 antibody-drug conjug ate SAR408701, the antibody moiety targets CEACAM5 on tumor cells. Upon antibody/antigen binding and internalization, the immunoconjugate releases the cytotoxic agent, which results in tumor cell death. CEACAM5, a member of the CEA family of proteins that plays a key role in cell migration, cell invasion, and cell adhesion, is overexpressed by a variety of cancer cell types. 